\title{
Assessing Wear and Surface Roughness of Different Composite
}

\section{Resins After Toothbrushing}

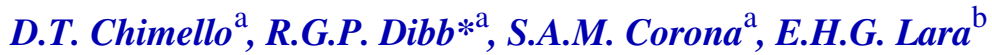 \\ ${ }^{\mathrm{a}}$ Faculdade de Odontologia de Ribeirão Preto da Universidade de São Paulo, \\ Departamento de Odontologia Restauradora. Av. do Café s $n$, Monte Alegre, \\ 14040-904 Ribeirão Preto - São Paulo, Brasil \\ ${ }^{\mathrm{b}}$ Faculdade de Ciências Farmacêuticas da Universidade de São Paulo, Departamento \\ de Ciências Farmacêuticas. Av. do Café s/n, Monte Alegre, \\ 14040-904 Ribeirão Preto - SP, Brasil
}

Received: March 13, 2001; Revised: August 8, 2001

\begin{abstract}
The aim of this work was to compare the in vitro wear and roughness of different composite resins after toothbrushing. Six resins were tested: Revolution (Kerr), Natural Flow (DFL), Flow It! (Jeneric-Pentron), Fill Magic Flow (Vigodent) - flowable composites, Silux Plus (3M) - microfilled composite, and Z100 (3M) - hybrid composite. Eight disks were prepared for each group $(\mathrm{n}=48)$, with $12 \mathrm{~mm}$ in diameter and $1 \mathrm{~mm}$ thick. The specimens were stored in distilled water at $37{ }^{\circ} \mathrm{C}$ for 7 days, polished (Super Snap), weighed and submitted to the initial roughness test. Each sample was fixed on plexiglass plates and subjected to simulated toothbrushing. After abrasion, the samples were removed from the plates, weighed and submitted to the post-abrasion roughness test. Statistical analysis was performed by using ANOVA and Tukey's test. Pearson's test was used to verify correlation between wear and roughness. Data showed a similar resistance to wear of Natural Flow and Z100, both presenting minimum mass loss and surface roughness. Silux Plus presented the roughest surface after toothbrushing.
\end{abstract}

Keywords: wear, roughness, composite resin, toothbrushing

\section{Introduction}

Research in the Esthetic Dentistry seeks to meet to the demands of the clinicians, who desire restorative materials with easier handling characteristics and superior physical, mechanical and esthetical properties. However, it is known that achieving all these characteristics in one material constitutes a difficult task.

A desirable property for a restorative material is the high resistance to wear. Clinically, the wear of a restoration may result from the centric and functional contacts, the attrition of food bolus, the interproximal contact areas, as well as toothbrushing (abrasion wear), by the action of toothbrush and dentifrice ${ }^{1-6}$. Wear is a complex process, since it involves abrasion, adhesion, fatigue, erosion and friction, which interact among themselves ${ }^{7,8}$.

Wear by toothbrushing can happen in restorations situated on any dental surface, however it is more common on the buccal surfaces of the teeth (class V restorations), since

*e-mail: rgpalma@ forp.usp.br these sites tend to receive a more intense action of toothbrushing. The abrasion resistance of a material can be evaluated through its mass loss and superficial smoothness, after a certain period of toothbrushing ${ }^{10}$. Rough surfaces can lead to the increase of plaque retention and staining. The superficial texture can also influence the esthetical properties of composite resins, since it affects the light reflectance and the apparent shade of a translucent material $^{2}$.

Several materials have been indicated for class V restorations, and the composite resins are the most used. The microfilled resins have been broadly indicated for this type of restoration, due to an easier polishing, which allows the presence of a flatter surface close to periodontum, as well as a low modulus of elasticity, allowing a greater deflection of tooth-restoration ${ }^{11}$. Another type of resin class V-indicated is the flowable composite. They are constituted by small particles that correspond to the ones of the traditional hybrid composites (hybrid fillers ranging from 0.1 to $1 \mu \mathrm{m}$, 
or microfillers from 0.02 to $0.04 \mu \mathrm{m})$. However, they differ from hybrid resins by having a smaller amount of inorganic filler, and consequently a higher matrix proportion, which provides low viscosity and high fluidity, besides a low modulus of elasticity ${ }^{2,12}$.

Due to the reduced filler content of the flowable composites, it is assumed that they could present a lower resistance to toothbrush abrasion than the composites with a larger amount of fillers.

Based on this hypothesis, the aim of the present work was the in vitro assessments of wear rate and surface roughness of different flowable composites, in comparison to a microfilled resin and a hybrid composite after toothbrush abrasion.

\section{Materials and Methods}

For the present study, six different composite resins were selected: Revolution(Kerr Corp., Orange, CA, USA), Natural Flow (DFL Ind. E Com. Ltda, Rio de Janeiro - RJ, Brazil), Flow It! (Jeneric-Pentron Inc., Wallingford - CT, USA), Fill Magic Flow (Vigodent S/A Ind. Com., Rio de Janeiro - RJ, Brazil) - flowable composites, Silux Plus (3M Dental Products, St. Paul - MN, USA) - microfilled composite and Z100 (3M Dental Products, St. Paul - MN, USA) - hybrid composite, used as control. The composition of the tested materials is shown in Table 1.

Eight samples were made for each material, totaling 48 specimens. They consisted of disks obtained with a teflon mold with $12 \mathrm{~mm}$ in diameter and $1 \mathrm{~mm}$ deep. Each material was inserted into the mold in one increment with an appropriate instrument. A glass slide was placed over the mold/resin under pressure and the material was lightcured (Curing Light XL 3000, 3M, Sedlbauer AG, Grafenau) for $40 \mathrm{~s}$, according to manufacturers' instructions, obtaining a flat surface. The samples were removed from the mold, stored in distilled water at $37^{\circ} \mathrm{C}$ for 7 days and after this period, the surfaces opposite to the glass slide were finished and polished with Super-Snap (Shofu Inc., Kyoto, Japan) sequential disks in decreasing abrasive or- der. Each specimen was weighed in an analytic electronic balance (Ohaus Corporation, Union - NJ, USA) to determine its initial mass in grams $\left(\mathrm{M}_{1}\right)$, and the initial surface roughness $\left(\mathrm{Ra}_{\mathrm{i}}\right)$ of each sample was measured with a roughness meter (Prazis, ARO S.A., Buenos Aires, República Argentina). For this purpose, each specimen was carefully fixed with wax on a metallic support and the needle situated at the extremity of the equipment's arm was positioned on the sample surface and programmed to trace a course of $4.8 \mathrm{~mm}$. Two additional measurements were accomplished by rotating the disk in an angle of $90^{\circ}$, and a mean was obtained from the three values.

For the wear test, each specimen was fixed on the center of a plexiglass slide with $50 \times 20 \mathrm{~mm}$ (in agreement with the dimensions requested by the toothbrushing machine), by adding a drop of monomer of acrylic resin (Artigos Odontológicos Clássico Indústria Brasileira, São Paulo SP, Brazil) on the surface of the plexiglass and the sample, pressing it against the plate. Plexiglass patterns with the same dimensions of the resin disks were also used in the abrasion test, as control for wear. The machine used for simulated toothbrushing was of Pepsodent type, developed at the Precision Workshop from the University of São Paulo - Ribeirão Preto (Fig. 1).

The toothbrush used was Kolynos (Kolynos do Brasil Ltda, S. B. Campo - SP, Brazil) with soft bristles, and as abrasive agent, a suspension of the Sorriso Branqueador (Kolynos do Brasil Ltda, S. B. Campo - SP, Brazil) dentifrice, with high abrasivity degree, and distilled water in a $1: 1$ proportion.

The specimens were randomly assigned into groups, and for each test it was used five resin samples and a plexiglass pattern, which were positioned inside the containers with $15 \mathrm{~mL}$ of the suspension. Toothbrushing was accomplished with horizontal movements of the toothbrush under a weight of $0.2 \mathrm{kgf}$ and a traveled course of $3.8 \mathrm{~cm}$. The rotation was of 2 cycles/s and the total time of toothbrushing was of $100 \mathrm{~min}$. Both slurry and toothbrush heads were replaced for every new sample.

Table 1. Restorative materials.

\begin{tabular}{llclcc}
\hline Name & Manufacturer & Lot & Type of Filler & $\%($ vol $)$ & Size $(\mu \mathrm{m})$ \\
\hline Revolution & Kerr Corp.- USA & 905255 & Barium glass; synthetic silica & $55 \%$ & 1 \\
Natural Flow & DFL Ind. e Com. Ltda. & 9908730 & Boro-aluminum silicate glass; synthetic silica & $43 \%$ & NA \\
Flow It! & Jeneric-Pentron Inc. & 26653 & Barium-boro-fluoro-silicate glass & $55 \%$ & 1.5 \\
Fill Magic Flow & Vigodent S/A Ind. e Com. & 01199 & Barium-aluminum silicate & NA & 0.7 \\
Silux Plus & 3M Dental Products-USA & 19990915 & Colloidal silica & $40 \%$ & 0.04 \\
Z100 & 3M Dental Products-USA & 9GM & Zirconium; silica & $71 \%$ & 1 \\
\hline
\end{tabular}

NA - Information not available. 


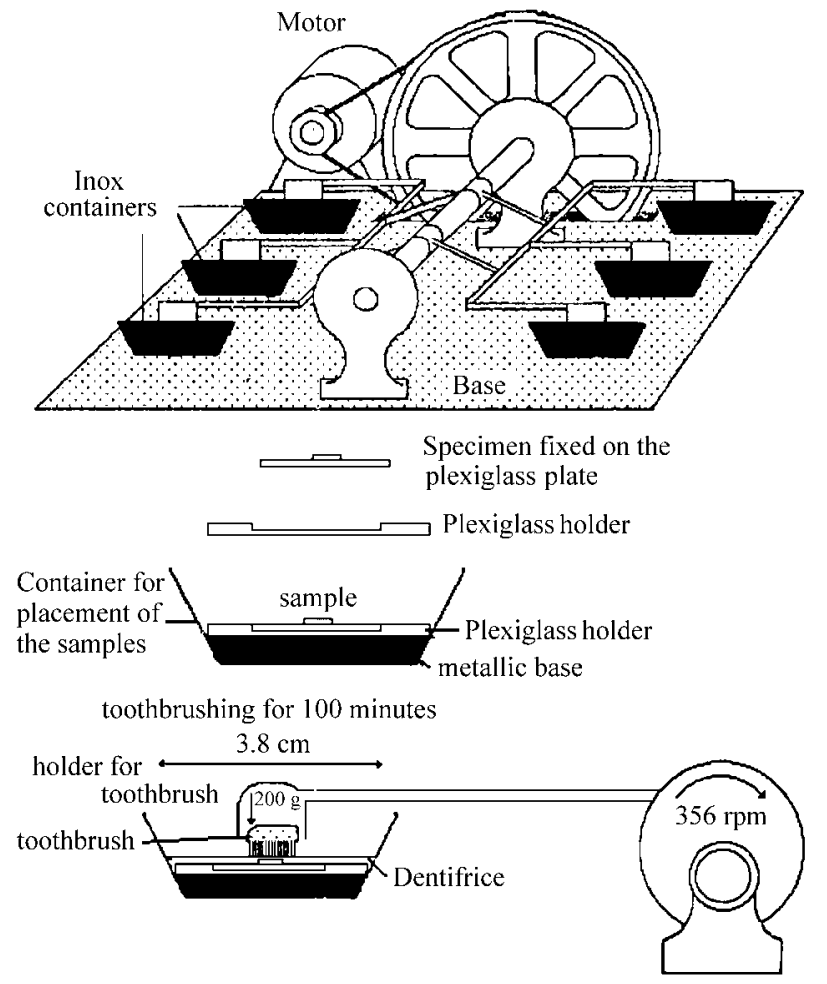

Figure 1. Line diagram of the toothbrushing apparatus.

After the test, the specimens were carefully removed from the plexiglass with the aid of a scalpel, rinsed in running water, dried and weighed, obtaining the final mass $\left(\mathrm{M}_{2}\right)$. The three measurements of post-abrasion roughness $\left(\mathrm{Ra}_{\mathrm{f}}\right)$ were accomplished following the same sequence described for the initial roughness test; however, the equipment's arm was positioned so that the tracing direction was perpendicular to the direction of the toothbrushing action, with the aim of registering the undulations caused by the abrasion procedure. The abrasion resistance was evaluated through the mass loss suffered by the material during toothbrushing $\left(\mathrm{M}_{1}-\mathrm{M}_{2}\right)$ and the averages of surface roughness (it was not possible to calculate the volume loss, since the manufacturers did not provide the density of the tested materials). The data were submitted to the Analysis of Variance (ANOVA) and Tukey's Test. The Pearson's Test was used to verify if there was any correlation between wear and roughness values.

\section{Results and Discussion}

The average of mass loss and superficial roughness of the different tested resins are listed in Tables 2 and 3.

With regard to wear, there was a statistically significant reduction $(\mathrm{p} \leq 0.05)$ of the mass of samples after toothbrushing. The minimum mass loss was observed in Natural Flow $(0.0038 \mathrm{~g})$, which presented a statistically similar result to Z100 (0.0061 g). Revolution, Flow It!, Silux Plus and Fill Magic Flow presented similar wear rates $(0.0091 \mathrm{~g}$, $0.0083 \mathrm{~g}, 0.0079 \mathrm{~g}$ and $0.0067 \mathrm{~g}$, respectively).

Analyzing the roughness averages, Revolution, Flow It!, Fill Magic Flow and Silux Plus presented a statistically significant increase $(\mathrm{p} \leq 0.05)$ in their surface roughness after abrasion. Natural Flow presented the lowest postabrasion roughness degree $(0.312 \mu \mathrm{m})$, being this result similar to that observed for Z100 $(0.499 \mu \mathrm{m})$. Silux Plus presented the roughest surface after the test $(3.278 \mu \mathrm{m})$, with significant difference. Revolution, Flow It! and Fill Magic Flow showed degrees of roughness situated between Z100 and Silux Plus. Additionally, the correlation between mass loss and surface roughness was found to be strong: $\mathrm{r}^{2}=0.34(\mathrm{p}<0.05)$.

Initially, all the tested composite resins presented a relatively low rate of surface roughness, since the procedures of finishing and polishing produced flat and polished surfaces. However, as expected, it was observed that toothbrush abrasion caused alterations on the surfaces of the samples in different degrees, according to the material. In this study, Natural Flow presented the greatest surface integrity after toothbrushing, with the least mass loss and the lowest surface roughness. In spite of having an amount of filler inferior to Z100, Natural Flow presented similar performance to the hybrid composite. According to Bayne

Table 2. Mass loss after toothbrush abrasion.

\begin{tabular}{llc}
\hline Material & Mean $(\mathrm{g})$ & Standard deviation \\
\hline Natural Flow & $0.0038^{\mathrm{a}}$ & \pm 0.0017 \\
Z100 & $0.0061^{\mathrm{ab}}$ & \pm 0.0018 \\
Fill Magic Flow & $0.0067^{\mathrm{bc}}$ & \pm 0.0016 \\
Silux Plus & $0.0079^{\mathrm{bc}}$ & \pm 0.0023 \\
Flow It! & $0.0083^{\mathrm{bc}}$ & \pm 0.0017 \\
Revolution & $0.0091^{\mathrm{c}}$ & \pm 0.0032 \\
\hline
\end{tabular}

Equal letters indicate statistical similarity.

Table 3. Initial and post-abrasion roughness averages of restorative materials.

\begin{tabular}{lcc}
\hline Material & Ra-i $(\mu \mathrm{m})$ & Ra-f $(\mu \mathrm{m})$ \\
\hline Natural Flow & $0.198( \pm 0.033)^{\mathrm{a}}$ & $0.312( \pm 0.108)^{\mathrm{a}}$ \\
Z100 & $0.114( \pm 0.053)^{\mathrm{a}}$ & $0.499( \pm 0.263)^{\mathrm{a}, \mathrm{b}}$ \\
Fill Magic Flow & $0.114( \pm 0.046)^{\mathrm{a}}$ & $0.835( \pm 0.379)^{\mathrm{b}, \mathrm{c}}$ \\
Revolution & $0.159( \pm 0.043)^{\mathrm{a}}$ & $0.872( \pm 0.44)^{\mathrm{b}, \mathrm{c}}$ \\
Flow It! & $0.137( \pm 0.052)^{\mathrm{a}}$ & $1.038( \pm 0.546)^{\mathrm{c}}$ \\
Silux Plus & $0.137( \pm 0.066)^{\mathrm{a}}$ & $3.278( \pm 1.945)^{\mathrm{d}}$ \\
\hline
\end{tabular}

Equal letters indicate statistical similarity. 
et al..$^{2,4}$, wear resistance is related to the interparticle space, as well as to the size and density of fillers. In the flowable composites, the interparticle space is reduced by the presence of small and joined fillers which protect the matrix, in spite of their volume percentage being of just 30 to $50 \%$ on average. Such fact could lead the flowable composites to present good results of wear. In their study, Bayne et al. ${ }^{2}$ did not observe statistically significant difference between flowable and traditional resins, all presenting a relatively low wear rate. Condon et al. ${ }^{3}$, Sulong et al. ${ }^{13}$ and Suzuki et $a l .{ }^{14}$ also suggested that small particles could provide some protection to the matrix against abrasion. This would happen because filler particles have a high modulus of elasticity and are abrasion-resistant, and when small enough, they can effectively reduce the spacing among them, which would protect the matrix ${ }^{4}$. On the other hand, $\operatorname{Rada}^{12}$ points that one of the concerns in relation to flowable composite resins is that they are not so resistant to wear when compared with more viscous composites. In the present study, it was observed that two of the tested flowable composite resins (Revolution and Flow It!) suffered a significant wear and presented surfaces rougher than the control hybrid resin.

In regard to mass loss, the microfilled composite Silux Plus presented a wear rate similar to the flowable composite resins (except Natural Flow), however, in agreement with several works ${ }^{6,15-18}$ it showed an inferior performance to the traditional hybrid resin.

According to $\mathrm{Aker}^{15}$, the size of filler particles can affect the resistance to abrasion. The author suggests that the volume loss is caused by the combination of the removal of the matrix and the eventual dislodgment of some particles as the matrix is worn away, and the big particles seem to hinder that removal.

Manhart et al. ${ }^{19}$ and Tanoue et al. ${ }^{20}$ observed that wear resistance of composite resins, could be influenced not only by filler content and size, but also by other factors such as matrix-filler interaction. Xie et al. ${ }^{21}$ assessed the wear resistance of glass-ionomer cements, and observed that bigger glass fillers and a better-integrated microstructure contributed to a greater wear resistance.

In a study ${ }^{1}$ about some chemically-cured resins with different types of filler, it was observed that a microfilled resin showed the greatest resistance to abrasion and presented the flattest surfaces after simulated toothbrushing. Gladys et al. ${ }^{10}$ found in their study a roughness value of $0.11 \mu \mathrm{m}$ for Silux Plus after abrasion, which was statistically similar to the hybrid composite (Z100).

Bayne et $a{ }^{4}{ }^{4}$ proposed that the protection supplied by the microfillers to the matrix can be endangered if they are agglomerated, increasing significantly the real interparticle spaces and decreasing consequently the effective resistance of the material. In the present study, a significant alteration on Silux Plus surface was observed, with accentuated grooves produced by the bristles of the toothbrush. This resin is constituted by particles of colloidal silica, which, in agreement with Phillips ${ }^{22}$, tend to agglomerate. Comparatively, Fortin et al. ${ }^{23}$ obtained in their recent study, a roughness value of $2.24 \mu \mathrm{m}$ for Silux Plus after toothbrushing.

However, in contradiction to our results, Ehrnford ${ }^{6}$ observed that a microfilled composite resin presented a comparatively flatter and more lustrous surface than the conventional resin, suggesting that this fact would have happened due to a more uniform wear of the former. This disagreement could be due to differences in the abrasivity presented by dentifrices.

Similarly to the present study, Mandikos et al. ${ }^{24} \mathrm{ob}-$ served a significant correlation between depth of wear and mean of surface roughness of some indirect composite resins after toothbrushing. They also suggested that the differences in wear, hardness and surface roughness could occur due to differences in the chemistry or in the light-curing methods.

\section{Conclusion}

Based on the results obtained, it can be concluded that only one flowable composite (Natural Flow) showed a similar behavior to the hybrid composite resin (Z100) in relation to surface integrity (wear and surface roughness), which was superior to the other tested materials. When compared with the microfilled composite (Silux Plus), Natural Flow presented less wear and a smoother surface. The other flowable composites (Revolution, Flow It! and Fill Magic Flow) showed similar wear rates to Silux Plus. However Silux Plus presented the roughest surface after toothbrushing.

This study suggests that greater or minor alterations on the material surface after toothbrushing with dentifrice depends on the composition and inherent characteristics of composite resins, being necessary the accomplishment of additional studies concerning the type, amount and arrangement of fillers, to verify the influence on the mechanical properties.

In general, the restorative materials investigated presented mass loss, leading to an increase of their roughness, showing a correlation between these two factors.

\section{Acknowledgement}

We wish to acknowledge Sr. José Orestes Del Ciampo, for the accomplishment of the toothbrushing test. We are 
also indebted to Jeneric - Pentron Inc., Vigodent S/A Ind. e Com. and FAPESP (proc. n. 99/06060-6).

\section{References}

1. Kanter, J.; Koski, R.E.; Martin, D. The relationship of weight loss to surface roughness of composite resins from simulated toothbrushing. Journal of Prosthetic Dentistry, v. 47, p. 505-513, 1982.

2. Bayne, S.C.; Thompson, J.Y.; Swift, E.J. Jr.; Stamatiades, P.; Wilkerson, M. A characterization of firstgeneration flowable composites. Journal of the American Dental Association, v. 129, p. 567-577, 1998.

3. Condon, J.R.; Ferracane, J.L. Evaluation of composite wear with a new multi-mode oral wear simulator. Dental Materials, v. 12, p. 218-226, 1996.

4. Bayne, S.C.; Taylor, D.F.; Heymann, H.O. Protection hypothesis for composite wear. Dental Materials, v. 8, p. 305-309, 1992.

5. Goldstein, G.R.; Lerne, T. The effect of toothbrushing on a hybrid composite resin. Journal of Prosthetic Dentistry, v. 66, p. 498-500, 1991.

6. Ehrnford, L. Surface microstructure of composite resins after toothbrush-dentifrice abrasion. Acta Odontologica Scandinavica, v. 41, p. 241-245, 1983.

7. Momoi. Y.; Hirosaki, K.; Kohno, A.; McCabe, J.F. In vitro toothbrush-dentifrice abrasion of resin-modified glass ionomers. Dental Materials, v. 13, p. 82-88, 1997.

8. Wassell, R.W.; McCabe, J.F.; Walls, A.W.G. Wear rates of regular and tempered composites. Journal of Dentistry, v. 25, p. 49-52, 1997.

9. Addy, M. Tooth hypersensitivity. Dental Clinics of North America, v. 34, p. 503-514, 1990.

10. Gladys, S.; Van Meerbeek, B.; Braem, M.; Lambrechts, P.; Vanherle, G. Comparative physico-mechanical characterization of new hybrid restorative materials with conventional glass-ionomer and resin composite restorative materials. Journal of Dental Research, v. 76, p. 883-894, 1997.

11. Van Meerbeek, B.; Perdigão, J.; Lambrechts, P.; Vanherle, G. The clinical performance of adhesives. Journal of Dentistry, v. 26, p. 1-20, 1998.

12. Rada R. The versatility of flowable composites. Dentistry Today, v. 17, p. 78-82, 1998.
13. Sulong, M.Z.A.M.; Aziz, R.A. Wear of materials used in dentistry: A review of the literature. Journal of Prosthetic Dentistry, v. 63, p. 342-349, 1990.

14. Suzuki, S.; Leinfelder, K.F.; Kawai, K.; Tsuchitani, Y. Effect of particle variation on wear rates of posterior composites. American Journal of Dentistry, v. 8, p. 173-178, 1995.

15. Aker, J.R. New composite resins: comparison of their resistance to toothbrush abrasion and characteristics of abraded surface. Journal of the American Dental Association, v. 105, p. 633-635, 1982.

16. Swartz, M.L.; Moore, B.K.; Phillips, R.W.; Rhodes, B.F. Direct restorative resins-a comparative study. Journal of Prosthetic Dentistry, v. 47, p. 163-170, 1982.

17. Leinfelder, K.F. Composite resins. Dental Clinics of North America, v. 29, p. 359-371, 1985.

18. Lambrechts, P.; Vanherle, G.; Vuylsteke, M.; Davidson, C.L. Quantitative evaluation of the wear resistance of posterior dental restorations: a new three-dimensional measuring technique. Journal of Dentistry, v. 12, p. 252-267, 1984.

19. Manhart, J.; Kunzelmann, K.H.; Chen, H.Y.; Hickel, R. Mechanical properties of new composite restorative materials. Journal of Biomedical Materials Research, v. 53, p. 353-361, 2000.

20. Tanoue, N.; Matsumura, H.; Atsuta, M. Wear and surface roughness of current prosthetic composites after toothbrush/dentifrice abrasion. Journal of Prosthetic Dentistry, v. 84, p. 93-97, 2000.

21. Xie, D.; Brantley, W.A.; Culbertson, B.M.; Wang, G. Mechanical properties and microstructures of glassionomer cements. Dental Materials, v. 16, p. 129-138, 2000.

22. Phillips, R.W. Skinner-Dental Materials. Guanabara Koogan, Rio de Janeiro, RJ, Brasil, p. 129, 1993.

23. Fortin, J.J.D.; Sang, J.; Hammesfhar, P.D.; Hughes, B. In vitro toothbrush abrasion of a new composite resin. Journal of Dental Research, v. 79, p. 279, 2000.

24. Mandikos, M.N.; McGivney, G.P.; Davis, E.; Bush, P.J.; Carter, J.M. A comparison of the wear resistance and hardness of indirect composite resins. Journal of Prosthetic Dentistry, v. 85, p. 386-395, 2001.

FAPESP helped in meeting the publication costs of this article 